\title{
Surveillance for Lyme disease in Canada: 2009-2015
}

\author{
Jules Koffi, Salima Gasmi \\ Public Health Agency of Canada, Saint-Hyacinthe, Quebec, Canada \\ Objective
}

This study aims to describe incidence over time, geographic and seasonal distribution, demographic and clinical characteristics of Lyme disease cases in Canada.

\section{Introduction}

Lyme disease (LD), a multisystem infection that is manifested by progressive stages [1], is emerging in central and eastern provinces of Canada due to northward expansion of the geographic range of Ixodes scapularis, the main vector in these regions [2]. In 2004, approximately 40 human cases of LD were reported in Canada. In 2009, LD disease became nationally notifiable, with provincial and territorial health departments reporting clinician-diagnosed cases to the Public Health Agency of Canada (PHAC). This study summarizes seven years (2009-2015) of national surveillance data for LD in Canada.

\section{Methods}

National Lyme disease surveillance data is collected through two surveillance systems, the Canadian National Disease Surveillance System (CNDSS) and the Lyme disease enhanced surveillance system (LDES). The CNDSS collects only demographic data (age and sex), and information on episode date and case classification. The LDES system captures additional data, including: possible geographic location of infection (for both locally acquired and travel-related cases); clinical manifestations; and results of laboratory testing. Nine provinces out of ten participate to LDES that means they provide a part of or all the data elements of this surveillance system. The 2009 national Lyme disease case definition [3] that distinguishes confirmed and probable cases (Table 1) is used to classify and report cases diagnosed by clinicians. This study describes the incidence over time, seasonal and geographic distribution, demographic and clinical characteristics of reported LD cases. Logistic regression was used to explore variations among age groups, sex and year of reporting clinical manifestations to better understand potential demographic risk factors for the occurrence of LD. Different models were used with as outcomes absence or presence of: erythema migrans (early Lyme disease), neurologic and cardiac symptoms and multiple erythema, migrans (early disseminated Lyme disease); and arthritis (late disseminated Lyme disease). The most parsimonious multivariate models were sought by backward elimination of nonsignificant variables until all factors in the model were significant $(\mathrm{P}<0.05)$.

\section{Results}

The number of reported LD cases increased more than six-fold, from 144 in 2009 to 917 in 2015, mainly due to an increase in infections acquired in Canada. For the provinces participating into the LDES system, the month of illness onset for Lyme disease cases acquired in Canada was available for 2010 cases. Most cases were reported during the summer months of June (20.7\%), July (35.4\%) and August (17.3\%) (Figure 1). An increase in incidence of LD was observed in provinces from Manitoba eastwards (Figure 2). This is consistent with our knowledge of range expansion of the tick vectors in this region. In the western provinces the incidence has remained low and stable. All cases reported by Alberta, Saskatchewan and Newfoundland and Labrador were acquired outside of the province, either elsewhere in Canada or abroad. There was a bimodal distribution for LD by age with peaks at 5-9 and 45-74 years of age (Figure 3). The most common presenting symptoms were a single erythema migrans rash (74.2\%) and arthritis (35.7\%) (Figure 4). In the multivariate analysis for clinical manifestations, children aged 0-9 years had a greater number of cases reported as early LD (erythema migrans only) than patients aged 10-19 and 30-39 years $(P<0.05)$. For early disseminated manifestations, young adults 20-29 years of age reported more neurologic manifestations, cardiac manifestations or multiple erythema migrans than the reference age group of $0-9$ years $(P<0.05)$. For late disseminated manifestations, children under 15 years of age were more frequently reported as having arthritis than other age groups.

\section{Conclusions}

Lyme disease incidence continues to increase in Canada as does the geographic range of ticks that carry the LD bacteria. This increasing of LD incidence might also be due to changing in knowledge, attitudes, and practices of clinicians who diagnose the disease and or of the public health workers who collect and report the data. Ongoing surveillance, preventive strategies as well as early disease recognition and treatment will continue to minimize the impact of LD in Canada.

SDS Annual Conference Proceedings 2019. This is an Open Access article distributed under the terms of the Creative Commons AttributionNoncommercial 4.0 Unported License (http://creativecommons.org/licenses/by-nc/3.0/), permitting all non-commercial use, distribution, and reproduction in any medium, provided the original work is properly cited. 
ISDS 2019 Conference Abstracts

\section{Acknowledgement}

The authors thank all the provincial and regional public health workers who collect and report data to the Public Health Agency of Canada.

\section{References}

1. Aguero-Rosenfeld ME, Wang G, Schwartz I, Wormser GP. 2005. Diagnosis of Lyme borreliosis. Clin Microbiol Rev. 18, 484-509. PubMed https://doi.org/10.1128/CMR.18.3.484-509.2005

2. Ogden NH, Koffi KJ, Pelcat Y, Lindsay LR. 2014. Environmental risk from Lyme disease in central and eastern Canada: a summary of recent surveillance information. Can Commun Dis Rep. 40(5), 74-82. http://www.phacaspc.gc.ca/publicat/ccdr-rmtc/14vol40/dr-rm40-05/ assets/pdf/14vol40_05-eng.pdf. PubMed https://doi.org/10.14745/ccdr.v40i05a01

3. Public Health Agency of Canada. Case definition for communicable diseases under National Surveillance. Ottawa: Public Health Agency of Canada; 2017. https://www.canada.ca/en/public-health/services/ reports-publications/Canadacommunicable-disease-report-ccdr/ monthly-issue/2009-35/definitions- communicable-diseases-nationalsurveillance/lyme-disease.html [Accessed 2017 Aug 17].

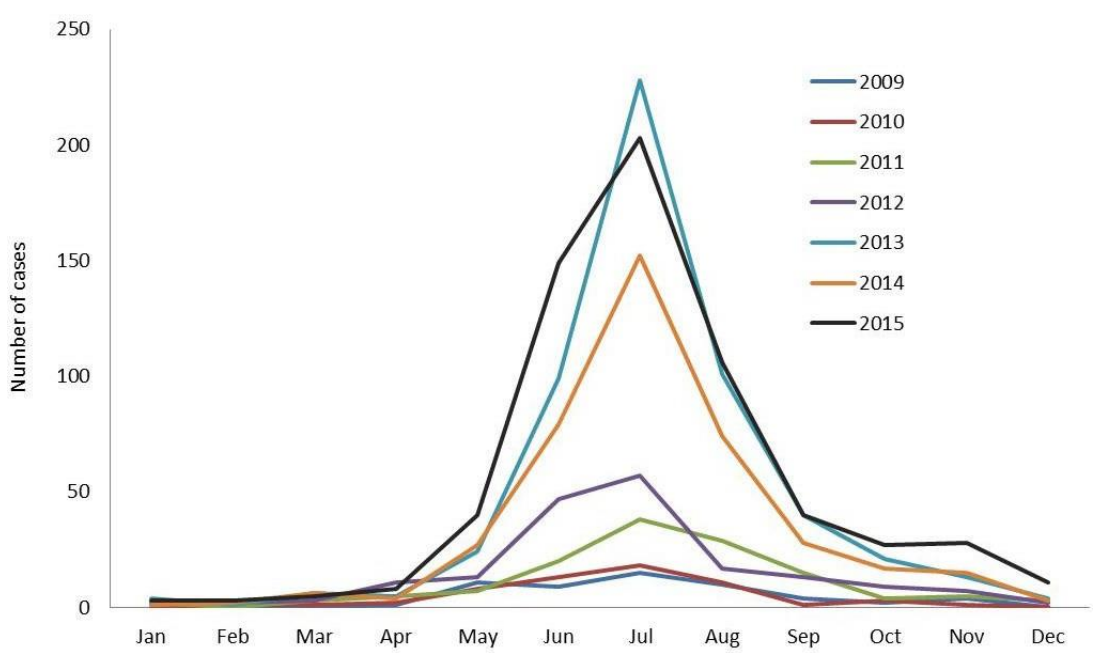

Figure 1: Month of Lyme disease illness onset for locally-acquired infection: Canada, 2009-2015 (n=2,010) 


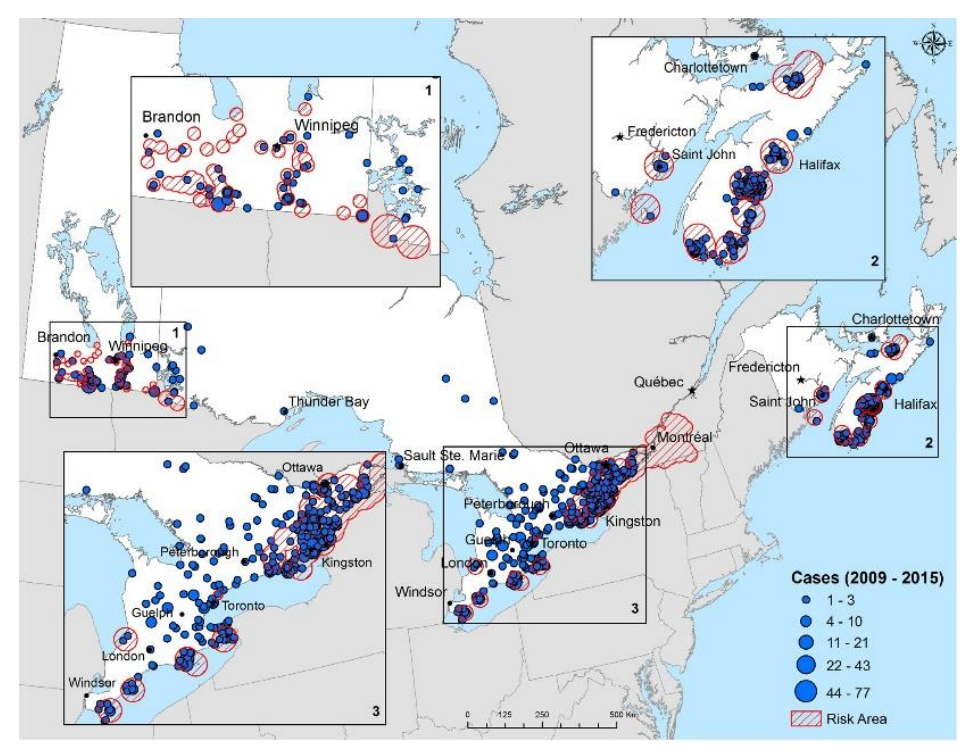

Figure 2: Reported locations of Lyme disease acquisition, Canada, 2009-2015

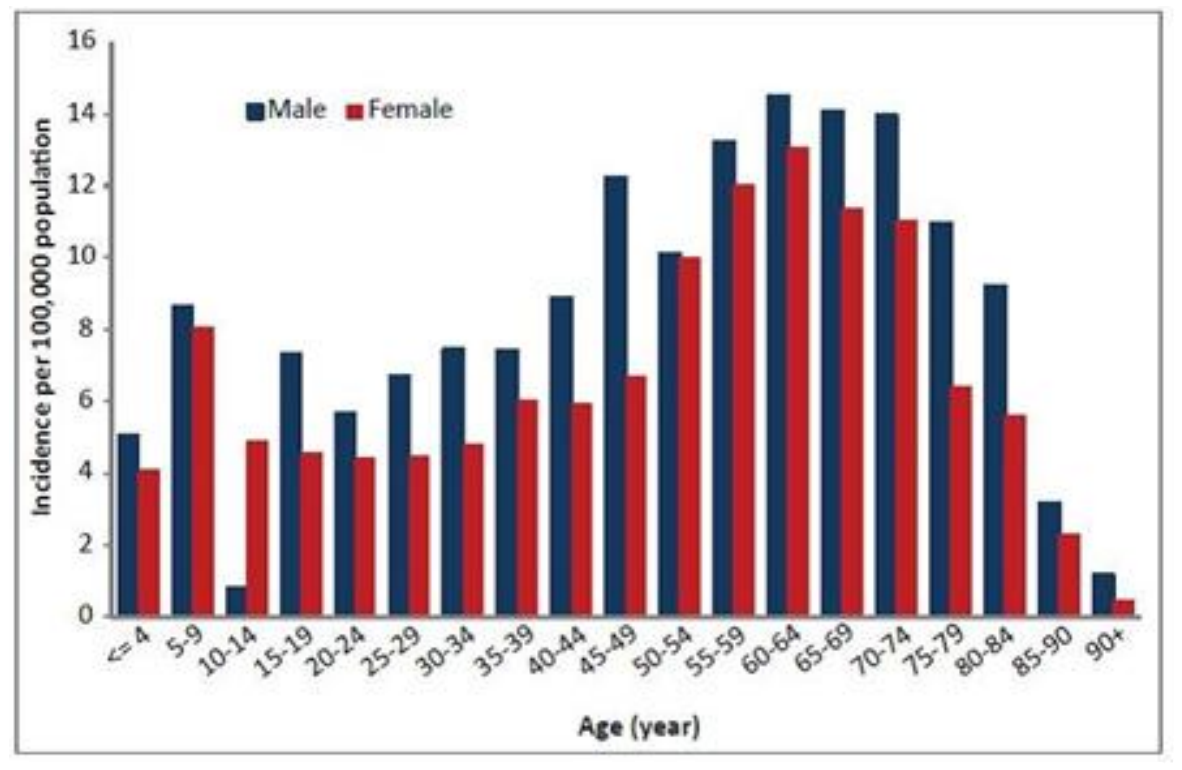

Figure 3: Incidence of Lyme disease by age group and sex, Canada 2009-2015 ( $n=3,004)$ 
ISDS 2019 Conference Abstracts

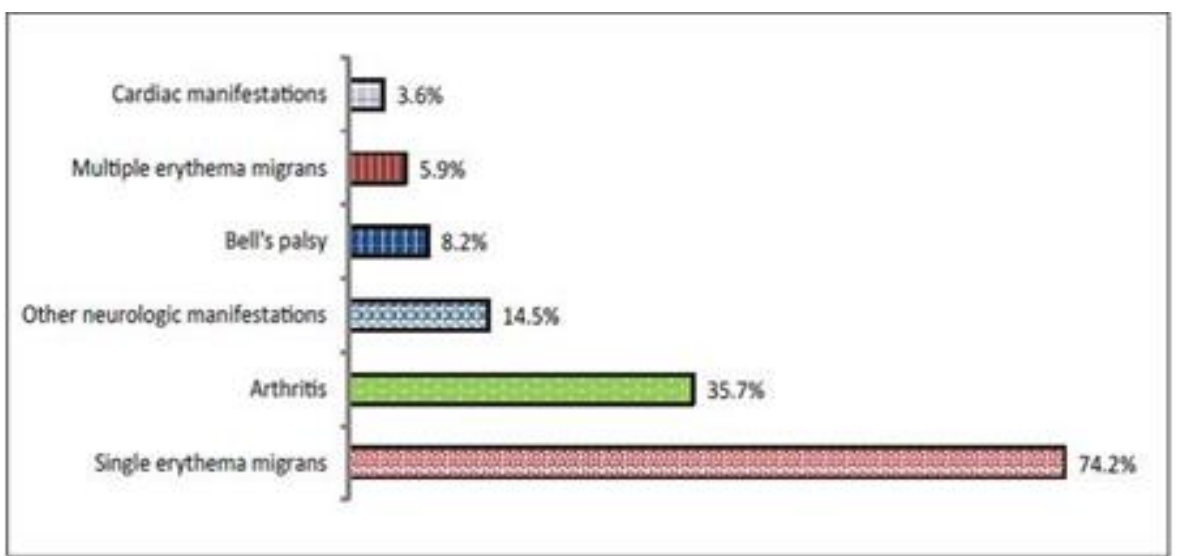

Figure 4: Percentage of clinical manifestations for Lyme disease infections acquired in Canada, 2009-2015 ( $\mathrm{n}=1,657)$

Table 1: 2009 national Lyme disease case definition

\begin{tabular}{|c|c|}
\hline Confirmed case & Probable case \\
\hline $\begin{array}{c}\text { Clinical evidence of illness with laboratory } \\
\text { confirmation: }\end{array}$ & $\begin{array}{l}\text { Clinical evidence of illness without } \\
\text { a history of residence in or visit to } \\
\text { an endemic area but with laboratory } \\
\text { evidence of infection: }\end{array}$ \\
\hline $\begin{array}{l}\text { isolation of } \\
\text { Borrelia burgdorferi from } \\
\text { an } \\
\text { appropriate clinical specimen }\end{array}$ & $\begin{array}{l}\text { positive serologic test using the } \\
\text { two-tier ELISA and Western } \\
\text { Blot criteria }\end{array}$ \\
\hline $\begin{array}{c}\text { OR detection } \\
\text { of B. burgdorferi DNA by PCR }\end{array}$ & $\begin{array}{l}\text { OR clinician-observed erythema } \\
\text { migrans without laboratory evidence } \\
\text { but with history }\end{array}$ \\
\hline $\begin{array}{l}\text { OR clinical evidence of illness with } \\
\text { a history of residence in, or visit } \\
\text { to, an endemic area and with } \\
\text { laboratory evidence of } \\
\text { infection, i.e., positive serologic } \\
\text { test using the two-tier ELISA } \\
\text { and Western Blot criteria }\end{array}$ & $\begin{array}{l}\text { of residence in or visit to an endemic } \\
\text { area }\end{array}$ \\
\hline
\end{tabular}

